\title{
PRÁTICAS SOCIALIZADORAS EM FAMÍLIAS POPULAES E A LONGEVIDADE ESCOLAR DOS FILHOS'
}

Maria José Braga Viana*

RESUMO: Este trabalho inscreve sua problemática no contexto mais amplo de compreensão de condições que possibilitam o fenômeno da longevidade escolar em famílias populares, discutindo alguns resultados de uma pesquisa que investigou a relação entre práticas socializadoras familiares e a constituição de disposições facilitadoras de sobrevida escolar nesses meios. A análise empreendida, construída a partir de dados extraídos de sete entrevistas em profundidade e de autobiografias escolares, direcionou o olhar para o modo de autoridade parental e para traços disposicionais dos sujeitos/alunos(as) entrevistados(as), mais especificamente, para as disposições à autonomia e temporais de futuro. No que concerne aos achados da pesquisa, o presente texto verticaliza num dos sete casos estudados e traz alguns temas transversais.

Palavras-chave: Camadas Populares. Longevidade Escolar. Práticas Socializadoras Familiares. Traços Disposicionais.

\section{SOCIALIZING PRACTICES IN LOW-INCOME FAMILIES AND THE SCHOOLING LONGEVITY OF THEIR CHILDREN}

ABSTRACT: The present work attempts to understand the phenomenon of schooling longevity, while looking in the broadest possible context at the conditions making this choice probable in low-income families, then discussing some research results that investigated the relationship between family socializing practices and the establishment of a disposition capable of facilitating schooling survival in this social class. The analysis was made, based on data collected during seven in-depth interviews and school reports. The focus was directed towards the quality of parental authority, identifiable and towards personality traits suggestive of the above-mentioned disposition that could be recognized in the interviewed subjects/students, in-particular, the following: autonomy; considerations about the future. Regarding these research findings, this article then chooses to focus in on one of the seven cases, and elucidates some common themes.

Keywords: Low-Income or Working Class. Schooling Longevity. Family Socializing Practices. Disposition or Personality Traits.

\footnotetext{
* Doutora em Educação pela Universidade Federal de Minas Gerais (UFMG) e professora associada do Departamento de Ciências Sociais Aplicadas à Educação da Faculdade de Educação da Universidade Federal de Minas Gerais (UFMG). E-mail: mj.braga@terra.com.br
} 


\section{Introdução}

Esse esboço de auto-análise não pode deixar de lado a formação das disposições associadas à posição de origem, das quais se sabe que, em relação aos espaços sociais em cujo interior elas se atualizam, contribuem para determinar as práticas. (BOURDIEU, 2005, p. 109)

Neste trabalho, exploro alguns dos resultados de uma pesquisa que buscou compreender a relação entre práticas socializadoras em famílias populares e a constituição de disposições facilitadoras de longevidade escolar nesses meios. Essa problemática situa-se no contexto mais amplo de compreensão de condições que possibilitam o fenômeno da longevidade escolar em meios populares.

Autores brasileiros (ALMEIDA, 2006; LACERDA, 2006; PIOTTO, 2007; PORTES, 1993; VIANA, 1998; SILVA, 1999; SOUZA, 2009; ZAGO, 2000, 2005) e estrangeiros (LAACHER, 1990; LAHIRE, 1997; 2005; LAURENS, 1992; TERRAIL, 1990; ZÉROULOU, 1988) vêm se debruçando sobre essa questão desde a década de 1990. Embora um número significativo de estudos sobre essa problemática mais geral a da longevidade escolar nos meios populares - já tenha sido realizado no contexto da realidade brasileira e por pesquisadores brasileiros (dissertações e teses), autores estrangeiros estão mais presentes na análise desenvolvida neste trabalho. Isso se justifica pelo objetivo central de discutir (outras) formas de presença das famílias populares na escolarização dos filhos, formas essas que foram investigadas na relação entre práticas socializadoras familiares e a constituição de disposições facilitadoras de sobrevida escolar nesses meios. Os autores estrangeiros escolhidos, sobretudo Thin (1998; 2006), abordam essa temática de maneira verticalizada, densa e empiricamente fundamentada.

Alguns desses estudos enfatizam os processos familiares de mobilização escolar como fator explicativo dessas escolaridades longevas (LAURENS, 1992; ZÉROULOU, 1988). Outros, no entanto, descobrem que é possível a produção desse fenômeno, mesmo na ausência de práticas familiares de investimento específico e intencional na carreira escolar (LAHIRE, 1997; VIANA, 1998). Concluí, então, que seria pertinente investigar a existência de um tipo particular de presença familiar na esco- 
larização dos filhos nesses meios. Considerando a hipótese de que as práticas socializadoras familiares podem se constituir num dos mais importantes terrenos para a localização de formas, pouco visíveis, de presença das famílias populares na escolarização dos filhos, busco investigálas enquanto lócus de constituição de disposições facilitadoras de sobrevida na escola.

Os dados trabalhados aqui foram extraídos de sete entrevistas em profundidade, com alunos egressos do curso de Pedagogia da Faculdade de Educação ( $\mathrm{FaE}$ ) da Universidade Federal de Minas Gerais (UFMG). Esses sujeitos foram selecionados no interior de um corpus de 120 autobiografias escolares, produzidas, de forma escrita, durante o segundo semestre de 2002 e o primeiro de 2003, num momento em que esses(as) alunos(as) ainda frequentavam a universidade. A coleta e a interpretação dos dados direcionaram o olhar para os seguintes aspectos: 1) as práticas socializadoras familiares, com foco no modo de autoridade familiar; 2) os traços disposicionais dos sujeitos entrevistados, mais especificamente, para as disposições à autonomia e temporais. Embora focalizando os dados das entrevistas, a análise que aqui se desenvolve considera também elementos das autobiografias.

Este trabalho é constituído das seguintes partes: uma breve revisão de literatura sobre o tema; a descrição de um caso singular identificado na pesquisa, o de Regina ${ }^{2}$; alguns dados transversais; e uma consideração final.

\section{Breve revisão de literatura sobre 0 tema}

Um tema tem sido recorrente nos estudos das relações das famílias populares com a escolaridade dos filhos: o de que os pais das famílias populares não são omissos e indiferentes em relação a ela. A presença das famílias populares na escolarização dos filhos tem sido constatada, podendo ser observada tanto na esfera do acompanhamento escolar stricto sensu quanto na esfera, menos visível, dos modos familiares de socialização, responsáveis pelo desenvolvimento, por exemplo, de disposições e competências (des)favorecedoras de longevidade escolar (LAHIRE, 1997; LAACHER, 1990). A concepção de "famílias populares" implícita neste trabalho se apoia basicamente nos estudos do campo da sociologia da educação. 
Assim, um pressuposto central é o da heterogeneidade interna dessas famílias, que não constituem um bloco monolítico, sobretudo no que se refere aos modos de criação dos filhos e a seu impacto na escolarização dos filhos, tema que interessa aqui.

Não vou me deter na revisão dos estudos que abordam o fenômeno da longevidade escolar no contexto de famílias populares "mobilizadas", mas daqueles que apontam para a existência de outras formas de presença familiar na escolarização dos filhos, assim como fornecem pistas para a investigação das mesmas.

Conforme referido, a omissão escolar dos pais das camadas populares é um mito produzido, sobretudo, pelos professores, especialmente quando aqueles são ausentes do espaço escolar. O termo "omissão", segundo Lahire (1997), é carregado de significado moralizador, que "remete a um voluntário, a uma escolha deliberada", o que não corresponde, segundo ele, ao que apreendeu em sua pesquisa. Assim, os pais não se mostraram ausentes da escolarização dos filhos, mesmo naqueles casos em que as dissonâncias entre o universo familiar e o escolar foram significativas, tendo contribuído para o fracasso escolar. Mesmo nesses casos, Lahire argumenta que "o fracasso escolar (...) não está necessariamente associado à 'omissão dos pais', mas a uma grande distância cultural e disposicional em relação às formas escolares de aprendizagem e de cultura" (p. 87).

Laacher $(1990,2005)$ desenvolve um estudo sobre trajetórias escolares bem-sucedidas de filhos de imigrados na França. Em função tanto da escolarização prolongada alcançada pelos filhos quanto das diferenças das experiências mais gerais de vida, entre elas a da própria imigração, instaura-se uma descontinuidade cultural e social entre pais e filhos. Essa descontinuidade implica que esses pais “(...) se constituam freqüentemente como um frágil recurso para as escolhas fundamentais que dizem respeito à escolaridade de seus filhos". Assim, continua Laacher, "nada lhes permite (...) se colocarem como mediadores e intérpretes da complexidade do funcionamento da instituição escolar", sobretudo para aqueles que alcançaram o ensino superior (p. 35). Essa pesquisa apresentou também duas constatações, aparentemente contraditórias: por um lado, uma ausência quase total dos pais no espaço escolar; por outro, reiterados depoimentos dos filhos de que estes estiveram sistematicamente "presentes" em sua trajetória escolar. Laacher defende que não há aí uma contra- 
dição, mas, diferentemente, defende a hipótese da existência de formas específicas de presença familiar na escolarização dos filhos, cuja natureza precisa ser identificada e descrita.

Já os estudos de Charlot (1996, 1997) e Charlot e Rochex (1996) constituem um referencial importante para se pensar a presença da família na escolarização dos filhos sob o prisma da produção de significados (des)mobilizadores em relação à escola. Esses autores defendem que a relação com o saber, com o aprender e com a escola é produzida, entre outros processos, no contexto de complexas demandas familiares, que podem sustentar ou dificultar a mobilização escolar do jovem. Uma forma de sustentação positiva estaria no fato, por exemplo, de que cada geração pode "autorizar", no plano do simbólico, a geração que lhe segue a ser diferente, a se emancipar das origens" (CHARLOT, 1996, p. 57).

Neste trabalho, busco focalizar as práticas socializadoras familiares, pressupondo uma assertividade das famílias populares em relação à escola - embora pressupondo também que a tensão, a contradição e a ambigüidade constituem traços fortes dessa relação (NOGUEIRA, 1991; DE QUEIROZ, 1981; THIN, 1998). Tenho como hipótese que essas práticas podem se constituir como um dos mais importantes terrenos para a localização de formas de presença das famílias populares na escolarização dos filhos, quando estes se encontram em situação de longevidade escolar. Essa presença está sendo pensada pela via da constituição de disposições facilitadoras, mais especificamente de disposições de autonomia e temporal ${ }^{3}$.

A constituição de um sujeito "autônomo" exige condições socioculturais específicas. Thin (1998) identificou alguns traços fortes do modo de socialização nas famílias populares que não seriam favorecedores dessa disposição. Um desses traços se caracteriza pelo "sentido prático", ou seja, um tipo de formação "não pedagógico", não normatizado por saberes teóricos, reflexivos, mas, diferentemente, processado diretamente nas atividades práticas, por imitação e imersão. Um modo de autoridade que se define pelas "sanções imediatas e contextualizadas" constitui outro traço. As sanções prevalecem sobre sua justificação; as punições são pouco discutíveis ou negociáveis: "a moral que é associada [à punição] ou que a subtende, não é explicitada, ou pouco explicitada” (p. 115). Ou seja, essas práticas não favorecem a interiorização de princípios de comportamento, de autonomia, porque "a autoridade é inseparável do 
contexto no qual ela se aplica" (p. 117). Finalmente, esse autor destaca como predominante o caráter estatutário da autoridade, que extrai sua justificação de uma divisão tradicional de papéis entre os membros da família; ou seja, "não é ele [o filho] que tem a última palavra, (...)" (THIN, 1998, p. 92). Swift (1968) argumenta, a esse respeito, de forma semelhante:

A educação dos filhos das classes sociais desfavorecidas tende a privilegiar a aceitação incondicional da autoridade dos pais. Estes tendem a se apoiar na punição física (...). Os filhos são pouco controlados em seus jogos e dispõem de um espaço importante de liberdade desorganizada. [Essa educação] não constitui uma maneira eficaz de controle de si. O filho vive a experiência de uma autoridade parcial, exterior e inexplicável (...), mais a entravar do que a favorecer o processo de adaptação escolar.

Como contraponto, tem-se o modo de socialização próprio da escola (VINCENT, 1994; VINCENT; LAHIRE; THIN, 2001; VIANA, 2004). Essa forma caracteriza-se centralmente por sua oposição ao modo de socialização prático, presente de forma contundente nas famílias de camadas populares, e por sua autonomia em relação às práticas socializadoras praticadas no contexto social mais amplo, o que confere a essa forma de socialização a característica de "relação pedagógica" (DE QUEIROZ, 1995; THIN, 1998; VINCENT, 1994). A interdependência entre o modo de socialização familiar e o escolar, produzida historicamente, pode estar na origem de situações de sucesso ou de fracasso escolar. No caso das camadas populares, essa interdependência produz uma confrontação desigual entre modos de socialização e estaria na origem de dificuldades na escola (THIN, 2006).

Quanto aos tipos de autonomia requeridos pela escola, Lahire (2005) adverte para a necessidade de se pensar sobre a natureza do seu objeto, ou seja, "em relação a que" está sendo considerada em cada caso, apontando dois tipos básicos de autonomia: cognitiva/comportamental, de um lado, e política, de outro. A autonomia cognitiva diz respeito à habilidade de fazer sozinho um exercício, de dar conta de se orientar por uma consigna escrita, de resolver por si mesmo um problema. Essas são, segundo o autor, propriedades disposicionais para agir e pensar no sentido escolarmente esperado (2005, p. 324). Já a autonomia política diz respeito às condições de trânsito nas regras de vida em comum, à respon- 
sabilidade, à (in)disciplina, à (im)possibilidade de negociação. As famílias das diferentes classes sociais se diferenciam em suas condições para produzir filhos/alunos responsáveis por seus atos, capazes de autodeterminação e de escolhas racionais ${ }^{4}$, disposições altamente valorizadas e requeridas pela escola. Assim, esse autor, no contexto de uma análise da "fabricação de um tipo de homem autônomo" a partir de dispositivos escolares, complexifica a análise da noção de disposição à autonomia, atribuindo-lhe diferentes sentidos e apontando para o fato da desigualdade entre os grupos sociais de possuir as condições sociais (mentais e comportamentais) favoráveis à sua construção.

Quanto às disposições temporais, trabalhei com a noção de horizonte temporal, que sinaliza para um "campo de projetos, de planificações, de previsões e de visões antecipadas, de expectativas e de esperanças" (MERCURE, 1995, p. 20-21). Viana (2007) conclui que a disposição dominante em relação ao futuro de jovens de camadas populares que empreenderam uma escolarização até a entrada no ensino superior foi a de "conquista", de horizonte temporal distendido. Se, justamente onde as condições de vida são mais precárias é que prevalece uma disposição dominante de reprodução em relação ao futuro, e, ao contrário, condições de vida que tornam o presente mais estável favorecem a elaboração de disposições e condutas de conquista (MERCURE, 1995), não há determinismo absoluto que dotaria os sujeitos das camadas inferiores com disposições conservadoras. Apesar das adversidades, indivíduos das camadas populares, embora estatisticamente minoritários, podem apresentar traços disposicionais transformadores diante do futuro e da vida em geral. $\mathrm{Na}$ presente pesquisa, buscou-se identificar práticas socializadoras familiares que facilitassem a constituição desse tipo de relação com o futuro.

Charlot (1999), discutindo a relação com o futuro entre jovens de camadas populares, constata que alguns deles buscam "ter acesso a uma vida normal", o que significa "ter um trabalho, um apartamento, um carro, filhos, férias... isto é, tudo o que as classes médias vivem com uma evidência, de tal forma que não chegam a constituir para elas um projeto". A luta por uma "vida normal" desses jovens se inscreve numa relação com o tempo que é, segundo o autor, "tática", uma vez que estão constantemente expostos a instabilidades e rupturas.

Em suma, mesmo predominando um confronto desigual entre famílias populares e escola no que diz respeito aos modos de socialização 
específicos em cada um desses universos, contraditórios muitas vezes, gerador, em potencial, de dificuldades escolares, busquei uma brecha de análise nas diferenças internas a essas mesmas famílias. Pressupus que, no bojo dessa heterogeneidade interna, poderiam emergir situações de menor distanciamento em relação à escola. O próprio Thin (1998) argumenta que a existência de um modo popular de socialização, com traços comuns, dominantes, não exclui a possibilidade de variações no interior das lógicas que tramam essa socialização, nem a heterogeneidade das práticas e, portanto, de universos familiares em menor contradição com as exigências escolares.

\section{0 caso de Regina}

Acredito que a primeira decisão em minha vida que não foi tomada por minha mãe foi o desejo de prestar vestibular. (Depoimento de Regina)

Regina tinha 53 anos no momento da entrevista ${ }^{5}$, realizada em 9 de maio de 2006, na Faculdade de Educação. Tem quatro irmãos, sendo ela a mais nova e a única mulher. Os pais, ambos falecidos, alcançaram a terceira série do Ensino Fundamental, cursada no interior de Minas Gerais, região rural. Nessa cidade, o pai trabalhou como operário da "Indústria do Açúcar do Álcool", antes de sua migração, e de toda a família, para Belo Horizonte. O pai faleceu quando Regina cursava a quarta série do Ensino Fundamental, com 10 anos. A mãe sempre trabalhou fora de casa, exercendo diferentes atividades: acompanhante de pessoas doentes, lavadeira, doméstica, parteira, costureira. A renda da família foi irregular a maior parte do tempo, mas de maneira mais forte após a morte do pai, quando ficou mais dependente dos baixos salários dos irmãos. $\mathrm{O}$ pai deixara de pensão o equivalente a meio salário mínimo.

Regina, a única entre os irmãos que fez o curso superior, não sofrera nenhuma reprovação, embora tenha interrompido os estudos após concluir a quarta série do Ensino Fundamental. O investimento decisivo que sua mãe conquistou para ela - assim como para seus irmãos - foi o acesso a um Colégio Militar de Belo Horizonte, onde cursou da quinta série ao final do Ensino Médio. Regina concluiu o Ensino Médio - moda- 
lidade Curso Normal - com 19 anos, tendo se submetido ao vestibular da UFMG no final desse mesmo ano, para Pedagogia, e tendo sido seleciona$\mathrm{da}$, sem frequentar cursinho pré-vestibular. Interrompeu o curso superior após frequentá-lo por dois anos, em função de seu casamento, com 22 anos. Só em 2002 retomou os estudos.

Com exceção de Regina, todos os irmãos concluíram a quarta série no interior, desenvolvendo trajetórias escolares sem reprovações, mas com interrupções, algumas definitivas. $\mathrm{O}$ irmão mais velho abandonou os estudos na quarta série, tornando-se soldado da Polícia Militar.

A mãe de Regina, tendo ficado viúva com os filhos adolescentes - Regina, caçula, com 10 anos -, teve de assumir sozinha a manutenção e a formação deles. Destaca-se como uma figura forte em suas práticas educativas - "brava, exigente, mandona, impositiva", segundo a filha - e por seu pesado investimento na escolarização dos filhos.

Em função de necessidade de tratamento de saúde para um dos filhos, a mãe de Regina mudou-se para Belo Horizonte, sendo acompanhada pelos outros filhos e pelo marido, um a um, ao longo de um período de aproximadamente quatro anos. Houve um tempo em que ela morou na capital sem o marido, com quatro filhos, sem renda própria suficiente, auxiliada pelo dinheiro do trabalho de dois filhos menores. A migração para Belo Horizonte implicou, naquele momento, a queda do nível de vida da família, sobretudo no que diz respeito à moradia. No interior, apesar do baixo salário do pai, a família morava em casa oferecida pela empresa onde ele trabalhava, numa vila de operários. Além de poder contar com "rede de esgoto, água encanada e luz elétrica", tinham atendimento médico e odontológico e dispunham de uma escola que atendia os filhos dos funcionários. "Quando a gente mudou para cá [Belo Horizonte], era um cômodo, aí... porque era uma casa de cinco cômodos, um cortiço (...) não havia nem fossa, nem banheiro (...)", comenta Regina.

\section{A autoridade familiar centrada na figura da mãe cuja "palavra era lei"}

Regina descreve sua mãe como uma figura extremamente forte e determinada. A busca insistente de vaga num Colégio Militar para os filhos, em Belo Horizonte, mostra bem essa determinação. No ano seguinte ao da conclusão da quarta série, Regina ficara sem alternativa de escola 
para prosseguir os estudos. Sua mãe empenhou-se então em conseguir uma vaga para a quinta série, para ela e para outros filhos, no Colégio Militar do bairro onde moravam. Para tal, utilizou a prerrogativa do cargo de soldado da Polícia Militar ocupado pelo filho mais velho. Os irmãos de Regina, candidatos à vaga, tinham, na época, 18, 16 e 15 anos. O fato de serem irmãos de um policial militar não lhes dava direito a pleitear essa vaga; teriam de ser filhos de militar. Mesmo assim, ela insistiu, chegando a se oferecer para lavar a roupa da casa do diretor da escola até os filhos se formarem, em troca das vagas pleiteadas. Vencida, ele aceitou que eles se submetessem a uma avaliação de admissão, no que foram bem-sucedidos.

Uma vez conquistada a oportunidade, ela "exigiu" que os filhos se aprovassem nessa seleção. Dizia; "olha, andei até não poder mais pra conseguir essas vagas; agora vocês não vão me envergonhar de jeito nenhum". A respeito, Regina argumenta: "se não acatasse... a gente tinha muito medo... na verdade, apanhar, apanhava pouco, porque tinha medo demais". A "exigência" colocada em relação a esse episódio ilustra o modo de autoridade que a mãe estabelecia sobre os filhos; o tom não era de negociação, de apelo, mas de intimidação e imposição.

De modo geral, a mãe de Regina se revelou militante em relação à escolarização dos filhos, objetivo para o qual ela colocava indiscutíveis condições, uma das quais a de que os irmãos partilhassem os mesmos livros didáticos. Como eles trabalhavam durante a tarde e iam direto do trabalho para o colégio, e Regina utilizava o livro nesse período do dia, ela tinha de estar na porta do colégio para repassá-lo aos irmãos, à entrada das aulas. Outra exigência materna em relação à escola era a de que Regina teria de fazer os deveres de casa para um dos irmãos, que, num certo momento, não conseguia conciliar o trabalho com os estudos. Regina lembra um depoimento da mãe a respeito: "o seu irmão vai perder porque não tá tendo tempo de fazer o dever, então você vai fazer; você vai fazer o seu de manhã e o dele; você vai dar conta, eles [os professores] não vão ficar sabendo".

A boa aparência dos filhos na escola constituía, para a mãe de Regina, outro campo de luta, a da (não)exposição de sua pobreza: "a gente é pobre, mas não pode passar atestado de pobreza; se você passa atestado de pobreza, as pessoas te humilham, (...) não é que vai falar que tem mais do que tem, mas também não precisa falar aquilo que não tem". 
Regina circunscreve essa exigência da mãe no quadro das seguintes condições objetivas de suas vidas: "nós morávamos no alto de um morro, muita terra, terra vermelha... aquilo que você andava... se fosse no sol, muito pó; se fosse na chuva, muito barro; a gente tinha que levar o calçado lá na rua, calçar pra não sair sujo, pra não aparecer sujo onde fosse". Ligada ainda à preocupação com a higiene e o com o "cuidado", e considerando as condições de moradia dessa família, havia também a preocupação da mãe com uma mesa para os filhos fazerem o dever de casa, e que fosse coberta com uma toalha para que o material escolar não ficasse sujo.

Não foi permitido que Regina trabalhasse enquanto estudava "em lugar que tem homem, principalmente", segundo ela interpreta o comportamento da mãe. Podia, ocasionalmente, cuidar de crianças da vizinhança, desde que fosse em sua própria casa. A mãe privilegiava para Regina trabalhos que se desenvolvessem em espaços frequentados por mulheres; a melhor opção era, então, ser professora, profissão que ainda conferia status. A mãe interferia também em escolhas importantes da vida de Regina. Quando concluiu a oitava série, Regina não pôde optar pelo Curso Científico, habilitação que o Colégio Militar oferecia, ao lado do Curso Normal. Ela deveria ser professora.

Só era permitido sair de casa quando fosse para realizar tarefas escolares, mas, mesmo nesse caso, a mãe "costumava chegar lá de surpresa" para conferir se a saída, de fato, era a propósito de estudo.

Regina não oferecia resistência aos ditames da mãe. "Não havia teimosia e se a gente ficasse chateada, ela falava: 'vai chorar na cama que é lugar mais quente"'. Pode-se concluir que havia uma subserviência diante das "exigências" da mãe por parte de Regina e de seus irmãos. O Colégio Militar que ela frequentara tinha um regime disciplinar muito rígido, o que reforçava esse modelo socializador. "Ela me pôs no lugar certinho", comenta.

A mãe de Regina achava que era possível superar as adversas condições materiais em que viviam - considerando que "ela (...) tinha horror da pobreza" - e que o caminho para a superação era a escola. Essa crença na escola como redentora aparecia reiteradamente em seu discurso. Expressa-se aí uma disposição à emancipação das condições materiais e culturais de existência e, à medida que os filhos iam conquistando melhores condições de vida por meio da escolarização, ampliava-se sua crença nessa possibilidade. Por exemplo, a propósito de um dos filhos, 
que se formou em contabilidade (nível técnico) e que montou o próprio escritório, ela declara: "se você for contador [que implica escolarização], você vai ser o dono do próprio escritório". Os outros filhos, embora tivessem concluído "apenas" a oitava série do Ensino Fundamental, conseguiram se afirmar em ocupação não manual, de escritório.

Havia mais do que uma crença na possibilidade de um futuro melhor para os filhos; havia, sim, uma "convicção", segundo Regina. Mas acreditava-se também que essa mobilidade social se efetivaria num tempo longo, o de gerações: "a gente tem que fazer pro filho, pro filho fazer mais pro filho dele, pro filho dele ser mais do que ele... porque assim a gente vai melhorando de vida".

Interiorizando essa disposição temporal de aposta no futuro com base nas próprias ações, Regina afirma, pensando o momento de sua entrada na universidade: “(...) parece que fica lá no seu inconsciente que você vai conseguir algo, se você prosseguir". Foi construída entre os membros dessa família uma disposição ascética voltada para a escola, tendo em vista o que ela pode oferecer em termos de superação das condições adversas de vida. No Colégio Militar, por exemplo, ela teve de vencer pesadas barreiras materiais e culturais: “(...) se era difícil, a gente tinha que arrumar jeito”. São exemplo as buscas na biblioteca pública, que era longe de casa e para onde eles iam a pé. Ela teve, também, de viver a experiência do confronto com o universo material e social de sua família. Embora "adaptada" na escola, não lhe era permitida a explicitação de um distanciamento:

Não levava colega minha na minha casa; eu só estudava com filhas de coronel, de major; mais pobre lá era o sargento e o meu irmão era um simples soldado; minha casa não tinha nada pra oferecer; aí era aquela história que a minha mãe sempre falava, não passa atestado de pobreza.

Nesse contexto inscreve-se a importância do uniforme escolar, que homogeneizaria a todos os alunos pela aparência, porque ocultaria a pobreza. Daí o cuidado de sua mãe para que ela e seus irmãos o portassem sempre "impecável": muito limpo, bem-passado, sapatos engraxados. "Aparentemente, eu não era tão pobre; [mas] eu, internamente, sabia que era diferente". Regina aprendera com a mãe a não exibir traços de pobreza, para não se expor à humilhação, ao ridículo.

O planejamento e o controle da renda familiar eram integralmente administrados pela mãe. Havia conflito com os filhos quando eles 
não se dispunham a repassar o dinheiro que recebiam do trabalho para ela. Essa resistência dos filhos quanto a esse repasse emergia, sobretudo, de uma vida extremamente gregária que ela construíra em sua casa. Frequentemente, a mãe de Regina abrigava em sua casa pessoas com dificuldade de sobrevivência, às vezes pela vida toda, como é o caso de uma moça que, acolhida grávida, acabou lá permanecendo pela vida inteira, assim como seu filho. Há também o caso de uma criança de três anos que, abandonada na porta de sua casa, lá fora criada. Os filhos se opunham a esse tipo de gregarismo, argumentando sobre as implicações que ele poderia ter nas possibilidades de melhoria de vida - "mãe, a gente trabalha e nunca vai ter nada porque a senhora gasta tudo com os outros" - e, na vida privada, sobretudo na divisão de espaços na casa, "A gente deita numa cama e não sabe aonde vai acordar", afirmavam os filhos.

No que dizia respeito à gestão do tempo cotidiano e das tarefas domésticas, a mãe de Regina tinha uma disposição mais hedonista. Não havia um controle do tempo dos filhos, nem divisão de tarefas domésticas entre eles. "Ela nunca brigou com a gente se dormisse até tarde", diz Regina. Como "a casa vivia sempre cheia", as pessoas que lá estivessem executavam as tarefas domésticas diárias. À Regina era permitido tempo livre para estudar; a cobrança sendo direcionada para os resultados escolares: “(...) isso era uma coisa que era solta, eu não tinha obrigação dentro de casa".

\section{Alguns temas transversais identificados}

Minha pesquisa limitou-se a focalizar as disposições e práticas socializadoras familiares, sem observar empiricamente o universo das disposições requeridas pelas escolas específicas que os sujeitos investigados frequentaram. Assim, essas disposições foram apenas deduzidas da teoria mais geral sobre a questão (VINCENT, 1994; VINCENT; LAHIRE; THIN, 2001). A título de sistematização final, destaco sumariamente os pontos que se seguem. 


\section{A não identificação de um modo de socialização familiar "puro"}

A investigação não identificou um modo de socialização familiar "puro", coerente, mas, muitas vezes, sincrético e/ou contraditório. Isso, seja considerando as contradições internas na mesma figura parental, seja considerando as diferenças entre o pai e a mãe. O que se identificou quase sempre foi um traço predominante no modo de socialização parental, centrado mais ora na figura do pai, ora na da mãe. As reiteradas práticas de castigo físico, por exemplo, tiveram, sobretudo, o pai como protagonista. Verificaram-se também mudanças de comportamento parental ao longo da história da família - a situação de pais “autoritários" que foram mais inflexíveis e severos com os filhos mais velhos - e/ou transformações nas práticas do pai especificamente, sobretudo aquelas mais rígidas, pela atuação mediadora da mãe.

\section{A relação entre socialização familiar e construção de disposição à autonomia}

Em primeiro lugar, identificou-se certo "autoritarismo" dos pais, na maioria das vezes ligado ao uso de castigos físicos. Para os entrevistados, o que define essas práticas como "autoritárias" é, basicamente, a impossibilidade de argumentação, de negociação, ou seja, a imposição de sanções com força estatutária. Numa análise mais apurada, no entanto, outras leituras desse "autoritarismo" podem ser feitas. Uma delas permite a identificação de elementos contraditórios nessas formas de socialização centradas, sobretudo, na figura do pai, que se mostrava sensível à negociação em determinadas circunstâncias. Outra interpretação possível é a da construção de significados ambivalentes, por parte dos filhos, em relação a esse modo de autoridade parental. Se, num momento da vida, sobretudo na infância e na adolescência, o pai foi concebido como despótico "um absurdo", para um dos sujeitos -, noutro momento, o do adulto atual, é afirmado como referência positiva de formação.

Em segundo lugar, a exortação ao trabalho precoce que apareceu na família do único sujeito investigado do sexo masculino. Aos 12 anos, fora "intimado" pelo pai a trabalhar. Segundo ele, o que movia o pai era o propósito de levá-lo, assim como a seus irmãos do mesmo sexo, a se autossustentarem, já que ele próprio assumia financeiramente a manutenção da casa. A minha hipótese é de que essa exigência con- 
tribuíra, de alguma forma, para a instauração, nos filhos, de certo grau de autonomia na vida.

Em terceiro lugar, o fenômeno da "família fechada nela mesma", identificado em algumas famílias ${ }^{8}$, em que havia uma interdição dos filhos de brincar com outras crianças na rua (na infância), de sair para festas, de receber pessoas em casa (na adolescência). Uma das explicações para esse fechamento estava na crença de que o mundo fora da família era ameaçador, de que havia sempre o risco de decadência moral dos filhos; outra explicação, ligada à anterior, estaria no objetivo de criar melhores condições de vida para eles, protegendo-os da "contaminação" externa.

Finalmente, a identificação de práticas socializadoras mais propícias ao aprendizado da autonomia. Numa delas, a entrevistada fora socializada num ambiente familiar onde, se ocorreram atitudes autoritárias por parte do pai, o que prevaleceu foi a ausência de rigidez. Aparece nos filhos - uma fratria de cinco irmãos em que todos concluíram o Ensino Superior - a interiorização de valorização do cumprimento de compromissos, sobretudo os escolares, que "aconteceu": "saía da gente, fluía...", afirma a entrevistada. Em outro caso, uma fratria de nove irmãos, em que apenas a entrevistada chegou ao Ensino Superior, a socialização familiar se apresentou mais homogênea, "liberal". Trata-se, a meu ver, de um caso mais evidente de socialização para a autonomia. A entrevistada recebeu responsabilidades, atribuídas pelos pais, como, por exemplo, a de cuidar dos irmãos mais novos, e teve permissão para sair de casa, inclusive para passar férias em casa de tios, em outras cidades, na adolescência.

\section{Relação entre socialização familiar e disposições temporais}

A esse respeito, concluo que práticas familiares favorecedoras da constituição de disposições temporais de futuro alargado foram uma marca forte de todos os casos estudados. O caso de Regina é exemplar a esse respeito. Esse horizonte temporal distendido teve como pano de fundo a crença na possibilidade de uma vida melhor para os filhos, expressa no discurso, mas também em indicadores objetivos, como: 1) a luta para escolarizar os filhos, embora, na maioria dos casos, tendo o Ensino Médio como o horizonte final; 2) a prioridade para os estudos em detrimento do trabalho; 3) os investimentos sistemáticos para superação das turbulências materiais ao longo da história da família; 4) a interdição 
ao ócio, ligada ao temor da decadência moral dos filhos; 5) o cuidado com a aparência física dos filhos, sobretudo na escola; o temor de não "parecer” pobre, para, entre outras razões, ultrapassar a própria pobreza.

\section{Consideração final}

Finalizo com um destaque de natureza metodológica: a dificuldade encontrada na pesquisa de identificar "disposições" e, ao mesmo tempo, práticas socializadoras que as tivessem engendrado. Todo o processo da pesquisa - desde a definição do protocolo para as entrevistas, passando pela descrição e pela análise dos dados levantados, até a decisão sobre a forma de escrita -, viu-se confrontado com ênfases, ora nas disposições ora nas práticas socializadoras familiares. Lahire (2004) fornece subsídio para a compreensão de tal "indecisão", quando afirma:

(...) uma disposição é uma realidade reconstruída que, como tal, nunca é observada diretamente; portanto, falar de disposição, pressupõe a realização de um trabalho interpretativo para dar conta de comportamentos, práticas, opiniões, etc. (...) Ao mesmo tempo, essas práticas são constituídas como tantos outros indicadores da disposição (p. 27).

Assim, em muitos momentos, vi-me identificando e descrevendo determinado tipo de disposição, mas com o cuidado de tratá-la como hipótese de disposição, uma vez que, apoiando-me em Lahire, reitero que a disposição nunca é observada diretamente, mas deduzida de práticas. 


\section{Referências}

ALMEIDA, Wilson Mesquita. Esforço contínuo: estudantes com desvantagens socioeconômicas e educacionais na USP. [2006]. Tese (Doutorado) - Universidade de São Paulo, São Paulo, 2006.

BOURDIEU, Pierre. Esboģo de auto-análise. Trad. Sérgio Miceli. São Paulo: Companhia das Letras, 2005.

CHARLOT, B. Qu'est-ce que est important pour eux? Qu'est-ce qu'ils attendent? Le rapport au temps. In: LE RAPPORT au savoir en milieu populaire: une recherche dans les lycées profissionnels de banlieue. Paris: Anthropos, 1999, p. 47-63.

CHARLOT, Bernard. Relação com o saber e com a escola entre estudantes de periferia. Trad. Neide Luzia de Resende. Cadernos de Pesquisa, São Paulo, n. 97, p. 47-63, 1996.

CHARLOT, Bernard; ROCHEX, Jean-Yves. L'enfant-éleve: dinamiques familiales et expérence scolaire. Lien Social et Poliques, RIAC, n. 35, p. 137-151, 1996.

DE QUEIROZ, Jean-Manuel. La désorientation scolaire: sur le rapport social des familles populaires urbaines à la scolarisation. Paris: Université Paris VIII, 1981.

DUBET, François; MARTUCCELLI, Danilo. Théories de la socialisation et définitions sociologiques de l'école. Revue Française de Sociologie,[S.1.], v. 37, p. 511-535, 1996.

HENRIOT-van Zanten, Agnès. Stratégies utilitaristes et stratégies identitaires des parents vis-à-vis de l'école: une relecture critique des analyses sociologiques. Lien Social et Poliques, RIAC, n. 35, p. 125-135, 1996.

LAACHER, Smaïn. L'école et ses miracles: Notes sur les déterminants sociaux des trajectoires scolaires des enfants de familles immigrées. Politix, Paris, n. 12, p. 25-37, 1990. LAACHER, Smaïn. L'institution scolaire et ses miracles. Paris: La Dispute, 2005.

LACERDA, Wânia Maria Guimarães. Famílias e filhos na construção de trajetórias escolares ponco prováveis: o caso dos iteanos. [2006]. Tese (Doutorado) - Universidade Federal Fluminense, Niterói, 2006.

LAHIRE, Bernard. Sucesso escolar nos meios populares: as razões do improvável. Trad. Ramon Américo Vasques e Sonia Goldefer. São Paulo: Ática, 1997.

LAHIRE, Bernard. Fabriquer un tipe d'homme"autonome": analyse des dispositifs scolaires. In: L'ESPRIT sociologique. Paris: La Découverte, 2005. p. 322-347.

LAHIRE, B. La théorie de l'habitus à une sociologie psychologique. In: LAHIRE, Bernard (Org.) Le travail sociologique de Pierre Bourdieu: Dettes e critiques. Paris: La Découverte, 2001. p. 121-152.

LAHIRE, Bernard. Retratos sociológicos: disposições e variações individuais. Porto Alegre: Artmed, 2004.

LAURENS, Jean-Paul. 1 sur 500: la réussite scolaire em milieu populaires. Toulouse: Presses Universitaires Du Mirail, 1992.

MERCURE, Daniel. Les temporalités sociales. Paris: Éditions L'Harmattan, 1995.

NOGUEIRA, Maria Alice; ABREU, Ramon Correa. Famílias populares e escola pública: uma relação dissonante. Educação em Revista, Belo Horizonte, v. 39, p. 41-60, 2004.

PAIXÃO, Lea Pinheiro. Estratégias de socialização: consonâncias e dissonâncias na relação família-escola. XII CONGRESSO BRASILEIRO DE SOCIOLOGIA (SBS). Anais... Belo Horizonte: UFMG, 2005.

PAVAN, Diva Otero. A produção do sucesso escolar: família, escola e classes populares. 
Pro-posições, Campinas, v. 9, n. 1, p. 45-71, 1998.

PIOTTO, Débora Cristina. As excę̧ões e suas regras: estudantes de camadas populares em uma universidade pública. [2007]. Tese (Doutorado) - Universidade de São Paulo, São Paulo, 2007.

PORTES, Écio Antônio. Trajetórias e estratégias escolares do universitário das camadas populares. [1993]. Dissertação (Mestrado em Educação) - Faculdade de Educação, Universidade Federal de Minas Gerais, 1993.

ROCHEX, Jean-Yves. Se sens de l'expérience scolaire: entre activité et subjectivité. Paris: PUF, 1995.

SETTON, Maria da Graça Jacintho. Um novo capital cultural: pré-disposições e disposições à cultura informal nos segmentos com baixa escolaridade. Educação \& Sociedade, Campinas, Cadernos Cedes, v. 26, n. 90, p. 77-105, 2005.

SILVA, Jaílson de Souza. Por que uns e não outros? Caminhada de estudantes da Maré para a Universidade. [1999]. Tese (Doutorado) - Pontifícia Universidade Católica do Rio de Janeiro, Rio de Janeiro, 1999.

SINGLY, François. O nascimento do "indivíduo individualizado" e seus efeitos na vida conjugal e familiar. In: PEIXOTO, Clarice E., SINGLY, François, CICCHELLI, Vincenzo (Orgs.). Família e individualização. Rio de Janeiro: FGV, 2000. p. 13-19.

SINGLY, François. Penser autrement la jeunesse. Lien social et politiques, RIAC, n. 43, p. 9-21, 2000.

SINGLY, François. L'appropriation de l'héritage culturel. Lien Social et Poliques, RIAC, n. 35, p. 153-165, 1996.

TERRAIL, Jean-Pierre. L issue scolaire: de quelques histoires de transfuges. In: Destins ouvriers: La fin d'une classe? Paris: Presses Universitaires de France, 1990, p. 223-258.

THIN, Daniel. Quartiers populaires: L'école et les familles. Lyon: PUL, 1998.

THIN, Daniel. Para uma análise das relações entre famílias populares e escola: confrontação entre lógicas socializadoras. Revista Brasileira de Educação, [S.1.], v. 11, n. 32, p. 211 225, 2006.

THIN, Daniel; MILLET, Mathias. La déscolarisation comme parcours de disqualification symbolique. In: GALSMAN, Dominique; OEURARD, Françoise (sous la direction). La déscolarisation. Paris: La Dispute/ SNÉDIT, 2004. p. 265-279.

THIN, Daniel; MILLET, Mathias. Ruptures scolaires: L'école à l'épreuve de la question sociale. Paris: PUF, 2005.

SOUZA, Maria do Socorro N. Medeiros. Do seringal à Universidade: o acesso das camadas populares ao ensino superior público no Acre. [2009]. Tese (Doutorado em Educação) Faculdade de Educação, Universidade Federal de Minas Gerais, Belo Horizonte, 2009.

VIANA, Maria José Braga. Longevidade escolar em famílias populares: algumas condições de possibilidade. Goiânia: Editora da Universidade Católica de Goiás - UCG/Fapemig, 2007.

VIANA, Maria José Braga. As relações entre famílias populares e escola: o lugar de uma confrontação desigual entre dois modos de socialização. Educação em Revista, Belo Horizonte, n. 40, p. 239-243, 2004.

VIANA, Maria José Braga. As práticas socializadoras familiares como locus de disposições facilitadoras de longevidade escolar em meios populares. Educação \& Sociedade, Campinas, Cadernos Cedes, n, 90, p. 107-125, 2005. 
VINCENT, Guy (Org.) L'Éducation prisonnière de la forme scolaire? Scolarisation et socialisation dans les sociétés industrielles. Lyon: PUL, 1994.

VINCENT, Guy; LAHIRE, Bernard; THIN, Daniel. Sobre a história e a teoria da forma escolar. Educação em Revista, Belo Horizonte, n. 33, p. 7-47, 2001.

ZAGO, Nadir. Do acesso à permanência no ensino superior: percursos de estudantes universitários de camadas populares. ANPED - GT SOCIOLOGIA DA EDUCAÇÃO, Anais... Caxambu, 2005.

ZAGO, Nadir. Quando os dados contrariam as previsões estatísticas: os casos de êxito escolar nas camadas socialmente desfavorecidas. Paidéia, Ribeirão Preto p. 70-80, 2000.

ZÉROULOU, Zaihia. La réussite scolaire des enfants d'immigrés: l'apport d'une approche en termes de mobilisation. Revue Française de Sociologie, [S.1], v. 29, n. 3, p. 447-40, 1988. 


\section{Notas}

${ }^{1}$ Este artigo constitui uma versão ligeiramente modificada de um trabalho apresentado na Conferência Internacional realizada pela International Sociological Association - IS A, em fevereiro de 2008, na Universidade Federal da Paraíba (UFPA), João Pessoa. Tendo contado com o apoio do CNPq e da Fapemig, o presente trabalho se inscreve no contexto de uma pesquisa integrada do OSFE (Observatório Sociológico Família-Escola), intitulada "A construção da longevidade e da excelência escolar em diferentes meios sociais processos e práticas de escolarização".

2 Os nomes são fictícios.

3 Lahire (2004) define "disposição" como o produto incorporado de uma socialização, de um "passado que se sedimentou, de alguma forma, e se converteu em maneiras mais ou menos duráveis de ver, sentir e agir, isto é, em características disposicionais: propensões, inclinações, hábitos, tendências, persistentes maneiras de ser" (p. 74).

4 De Singly (2000) situa a discussão da constituição da autonomia entre os jovens contemporâneos ("se tornar adultos", se "individualizar") num quadro complexo, o de uma dissociação com a independência, material e simbólica, sobretudo nos grupos sociais mais desfavorecidos.

5 A idade da entrevistada, "avançada" se considerada ao momento próximo de conclusão do seu curso de Pedagogia, se explica, como se verá a seguir, por uma longa interrupção dos estudos em função de seu casamento.

6 Este resultado corrobora resultados do estudo de Portes (1993).

7 Um dos grupos familiares identificados por Terrail (1990) apresentou esse traço como central.

Recebido: 30/09/2010

Aprovado: 18/08/2011

Contato:

Universidade Federal de Minas Gerais

Faculdade de Educação

Avenida Antônio Carlos, 6627

CEP $31270-901$

Belo Horizonte, MG

Brasil 